\title{
Incorporating UTAUT Predictors for Understanding Home Care Patients' and Clinician's Acceptance of Healthcare Telemedicine Equipment
}

\author{
Anne Kohnke', Matthew L. Cole², Richard Bush ${ }^{3}$
}

\begin{abstract}
Telemedicine programs within health care are experiencing significant growth as healthcare organizations seek to reduce expenditures and improve efficiency. The high costs of treating chronic diseases, compounded by an aging population, has given focus to creating technology-enabled alternatives to support, enhance, or expand patient services. As investments in telemedicine products and services grow at a rapid pace, user technology acceptance has become a key issue in successful implementation. Drawing from the Unified Theory of Acceptance in Technology (UTAUT), this study investigated the predictors of behavioral intention to use Telehealth equipment by patients, clinicians, and agency personnel at Henry Ford e-Home Health Care. Survey data were provided by 126 participants recruited from an eligible population who were either currently using the Telehealth equipment or were familiar with it. Structural equation modeling was used to study the overall fit of the UTAUT model in predicting behavioral intention. Participant type, self-efficacy, anxiety and attitude were tested as moderators. Implications for increasing adoption of Telehealth technology are discussed.
\end{abstract}

Keywords: telemedicine; information technology acceptance; UTAUT; information technology management in health care. 


\section{Introduction}

Telemedicine programs within healthcare are experiencing significant growth as healthcare organizations seek to reduce expenditures and improve efficiency. The high costs of treating chronic diseases, compounded by an aging population, has given focus to creating technology-enabled alternatives to support, enhance, or expand patient services (Nundy et. al., 2012; Or et. al., 20I I; Tompkins \& Orwat, 2010). Although telemedicine has been practiced for over forty years, with the advancements in technology, patients have a wide variety of services and medical information available to them like never before. At its earliest beginnings, a nurse or physician providing medical advice over the telephone was practicing telemedicine. Now, web-based portals provide access to high-resolution images, video, audio capabilities, and interactive communications with medical providers. Telemedicine offers great potential for enhancing healthcare and reducing costs.

Telemedicine is defined as remote monitoring, real-time interactive services, and data capture of medical information that is electronically forwarded to physicians and health care professionals. The growth of technology-assisted care is being driven by reducing costs, reducing hospital readmissions, and tracking disease progression (Hertz, 20/3). Studies indicate that telemedicine reduces hospital and emergency room visits, resulting in better patient outcomes (Charles, 2000; Viswanathan et al., 2009). According to the American Medical Association, over $65 \%$ of emergency room visits are not critical, and as many as $70 \%$ of all doctor visits could have been handled over the telephone (Hsia, Kellerman, \& Shen, 20l I). Increasingly, chronically ill patients are using emergency rooms as their primary source of care; the goal of an emergency room should be critical care and not as an outpatient care provider (Hertz, 20I3; O'Reilly, 20II). Under the Affordable Care Act, the Centers for Medicare and Medicaid Services (CMS) will penalize hospitals for excess readmission rates starting in 2013. Therefore, the adoption and use of telemedicine may prevent future unnecessary readmissions by enabling health care providers to monitor patient conditions remotely.

The use of advanced telecommunications technologies to exchange medical information allows for the provision of healthcare services across social and geographic barriers. For example, in rural areas where caregivers typically spend a large percentage of work hours traveling to patients' homes, telemedicine equipment can reduce the need for travel by monitoring patients with chronic illnesses such as congestive heart failure, chronic obstructive pulmonary disease, and diabetes. Telemedicine devices monitor health by collecting and transmitting patient physiological data (such as pulse, blood pressure, respiration, weight, and other fac- tors) directly to the care provider who may then take appropriate action. Telemedicine software applications deliver patient data via telephone and web-based solutions that can be accessed by consumer tablet computers, laptops, and even smart phones.

\section{Purpose of Study}

As investments in telemedicine products and services grow at a rapid pace, user acceptance of technology has become a key issue in the successful implementation of telehealth equipment (Wills, El-Gayar, \& Bennett, 2008; Zai et al., 20I3). Consequently, there is a growing need to better understand factors that contribute to positive user acceptance of telemedicine innovations. The purpose of this study was to draw from the Unified Theory of Acceptance in Technology (UTAUT) in order to investigate predictors of the behavioral intention to use telehealth equipment. We conducted this research in cooperation with Henry Ford at Home eHome Care which offers a telehealth remote monitoring program to enable patients to better manage their chronic diseases. Henry Ford at Home is Michigan's largest home health group with 700 caregivers and is part of the $\$ 4.5$ billion Henry Ford Health System located in Southeast Michigan. The aim of this study was to apply the UTAUT model to understand the intentions of clinicians, patients and agency leadership to use the telemedicine equipment in the Henry Ford e-Home Care organization.

\section{Literature Review \\ Acceptance of Technology Models}

The past three decades has seen an emergent area of focus within information technology research concerning the factors and the values associated with adoption, deployment, management, and effectiveness of a technology (BurtonJones \& Hubona, 2005; Leong, 2003). In support of Davis'(1989, p. 320) inquiry, "What causes people to accept or reject technology?", the adoption and use of technology has received fairly extensive attention from information technology researchers and practitioners (e.g., Brancheau, Janz, \& Wetherbe, 1992; Hartwick \& Barki, 1994; Markus \& Keil, 1994; Pavlou \& Fygenson, 2006). The coupling of people and technology has led researchers and practitioners to include the disciplines of psychology and sociology in their focus on how individual human and social behavior impacts theories and models of technological adoption. As an example, the Theory of Reasoned Action (TRA), an early theory of individual acceptance of technology, draws from psychology and posits that an individual's behavior is determined by one's intention to perform the behavior. The identification of determinants of intention includes attitudes, social influences, and facilitating conditions (Ajzen \& Fishbein, 1980; Fishbein \& Ajzen, 1975). A descendant of TRA is the Theory of Planned 
Behavior (TPB) which adds the construct of perceived behavioral control to the TRA model as another antecedent of intention. Perceived behavioral control is determined by the availability and importance of opportunities, resources and skills to achieve outcomes (Ajzen, 199I). In response to Triandis' (1977) study of human behavior which found that interactive behavior is determined more by behavioral habits than by attitudinal factors, theorists have proposed a competing perspective to the TRA and TPB models by seeking to predict usage behavior rather than behavioral intention. Specifically, Thompson, Higgins, and Howell (199I) developed the Model of PC Utilization (MPCU) to predict usage behavior. The MPCU refined Triandis' model and adapted it for use in information systems contexts. From this stream of research, the Technology Acceptance Model (TAM) emerged as the first theory developed to predict user acceptance by focusing on perceived usefulness and the perceived ease of use of technology, which are theorized to be fundamental determinants of user acceptance (Davis, 1989).

In their analysis of technology acceptance and planned behavior, Taylor and Todd (1995) compared the TAM and two variations of the TPB to understand usage of information technology. They found that all three models provided comparable fit and identified possible indirect effects on behavior, such as attitude (from both TAM and TPB), subjective norm (i.e., social influence for TPB only), as well as their antecedent beliefs (i.e., ease of use, perceived usefulness, and compatibility). The Combined TAM-TPB Theory of technology acceptance evolved out of this work to include the predictive elements of TPB with the concept of perceived usefulness from TAM (Taylor and Todd, 1995). TAM was further extended to TAM 2 incorporating additional theoretical constructs spanning social influence processes (subjective norm, voluntariness, and image) and cognitive instrumental processes (job relevance, output quality, result demonstrability, and perceived ease of use) (Venkatesh \& Davis, 2000).

\section{The UTAUT Model}

The most recent model to emerge from research on the adoption, deployment, management, and effectiveness of a technology is the Unified Theory of Acceptance and Use of Technology (UTAUT)(Venkatesh, Morris, Davis, \& Davis, 2003). The UTAUT integrates eight user acceptance models: theory of reasoned action (TRA), the technology acceptance model (TAM), the motivational model (MM), the theory of planed behavior (TPB), a model combining the technology acceptance model and the theory of planned behavior (CTAM-TPB), the model of PC utilization (MPCU), the innovation diffusion theory (IDT), and the social cognitive theory (SCT). The UTAUT model set out to capture the essential elements of these eight previously established models.
The UTAUT model was derived from longitudinal data obtained from 215 individuals in six organizations who were introduced to a new technology in the organization. From an initial set of 32 main effects and four moderators (gender, age, experience and voluntariness of use), Venkatesh et al. (2003) derived a model that was comprised of four primary constructs that were direct determinants of intention and usage behavior: performance expectancy (PE), effort expectancy $(\mathrm{EE})$, social influence (SI), and facilitating conditions (FC). In this study, we define PE as the perceived usefulness of a technology, and in particular, the degree to which the participant believes that using the telehealth equipment will help him or her manage health and enhance job performance. Performance expectancy is conceptually and empirically identical to perceived usefulness from TAM (Venkatesh, et. al., 2003). Studies of technology acceptance in other fields have consistently found that when participants perceive a technology as useful, then the likelihood of accepting the technology increases (Holden and Karsh, 2010; jimison \& Sher, 2008; Venkatesh, et. al., 2003). EE is defined as the perceived ease of use of a technology, and specifically, the degree to which the telehealth equipment is easy to use. Effort expectancy is conceptually and empirically identical to perceived ease of use from TAM (Venkatesh, et. al., 2003). Prior research suggests perceived ease of use is a positive predictor of technology acceptance (Thakur, 2013; Wills, et al., 2008). We define SI as the degree to which clinicians and caregivers support participant's use of the telehealth equipment. SI includes three conceptually identical constructs mapped from the previous models: subjective norm (TRA, TAM2, TPB, and C-TAM-TPB), social factors (MPCU), and image (IDT). SI was shown to be a significant factor in determining the acceptance and use of technology (Ajzen, I991; Moore \& Benbasat, 1991; Taylor and Todd, 1995; Venkatesh, et. al., 2000). Finally, FC is defined as the degree to which the participant believes they have the cognitive and physical ability to use the telehealth equipment, and that technical support is available when needed. Similar to SI, FC also includes three conceptually identical constructs mapped from the previous models: perceived behavioral control (TPB, CTAM-TPB), facilitating conditions (MPCU), and compatibility (IDT). Studies examining acceptance and use of technology have shown that FC significantly predicts acceptance and use of technology (Mathieson, 1991; Taylor and Todd, 1995).

\section{Attitude,Anxiety, and Self-Efficacy as Moderators}

Attitude refers to the participant's positive or negative feelings about performing an activity, such as the use of the telehealth equipment to report their medical data. Elias, Smith and Barney (2012) define attitude as an evaluative judgment, either favourable or unfavourable, that an individual possesses and directs towards some attitude object. A positive attitude about the use of the telehealth equipment 
ensures that patients and clinicians will use the equipment effectively. Attitude has shown to be a strong predictor of behavioural intention and has received substantial empirical support (Ajzen \& Fishbein, 1980; Davis et al 1989; Pavlou \& Fygenson, 2006).

While anxiety refers to the participant's self-reported hesitation when using the telehealth equipment, self-efficacy refers to the participant's judgment of their ability to use the telehealth equipment. When a patient or clinician has a negative attitude towards the technology they are encouraged or required to use, it is likely that they view the technology as a source of anxiety. Thus, patients and clinicians will have low intention to use the technology.

The construct of self-efficacy has recently emerged in the IT domain as an important construct. Self-efficacy is defined as an individual's belief about his or her capability to perform a behavior that exercises influence over events (Bandura, 1994). Compeau and Higgins (1995) define computer self-efficacy as the judgment of one's capability to use an information system. Self-efficacy has been strongly associated with perceived ease of use from TAM (Ong, et al., 2004) and perceived behavioral control from TPB (Taylor \& Todd, 1995). Self-efficacy beliefs determine how people think, feel, become motivated, and behave, and it is likely to have an important influence on the intention to use information technology and actual use behavior.

\section{Research Model and Hypotheses}

The research model for this study used the four primary constructs of the UTAUT model (PE, EE, SI, and FC) as predictors of behavioral intention $(\mathrm{BI})$ to use telemedicine equipment (see Figure I). Venkatesh et al. (2003) developed the UTAUT model in which PE, EE, and SI predicted $\mathrm{BI}$, and FC predicted Use Behavior. In the current study, systems logs and other indicators of Use Behavior were not available. Therefore, we have combined PE, EE, SI and FC into a latent variable that predicts BI.Additionally, to extend the UTAUT model to a wider range of moderators than was previously studied by Venkatesh et al., we used role, attitude, anxiety, and self-efficacy as moderators.

This study extends the previous research of behavioral intention to use technology to include the behavioral intention to use telehealth equipment. Additionally this study tests the UTAUAT model as a predictor of behavioral intention by using a robust statistical modeling technique, structural equation modeling. Finally, this study advances the set of variables that may potentially moderate the impact of UTAUT as a predictor of intention by testing participant role, attitude, anxiety, and self-efficacy as moderators. The following hypotheses were proposed for this study:

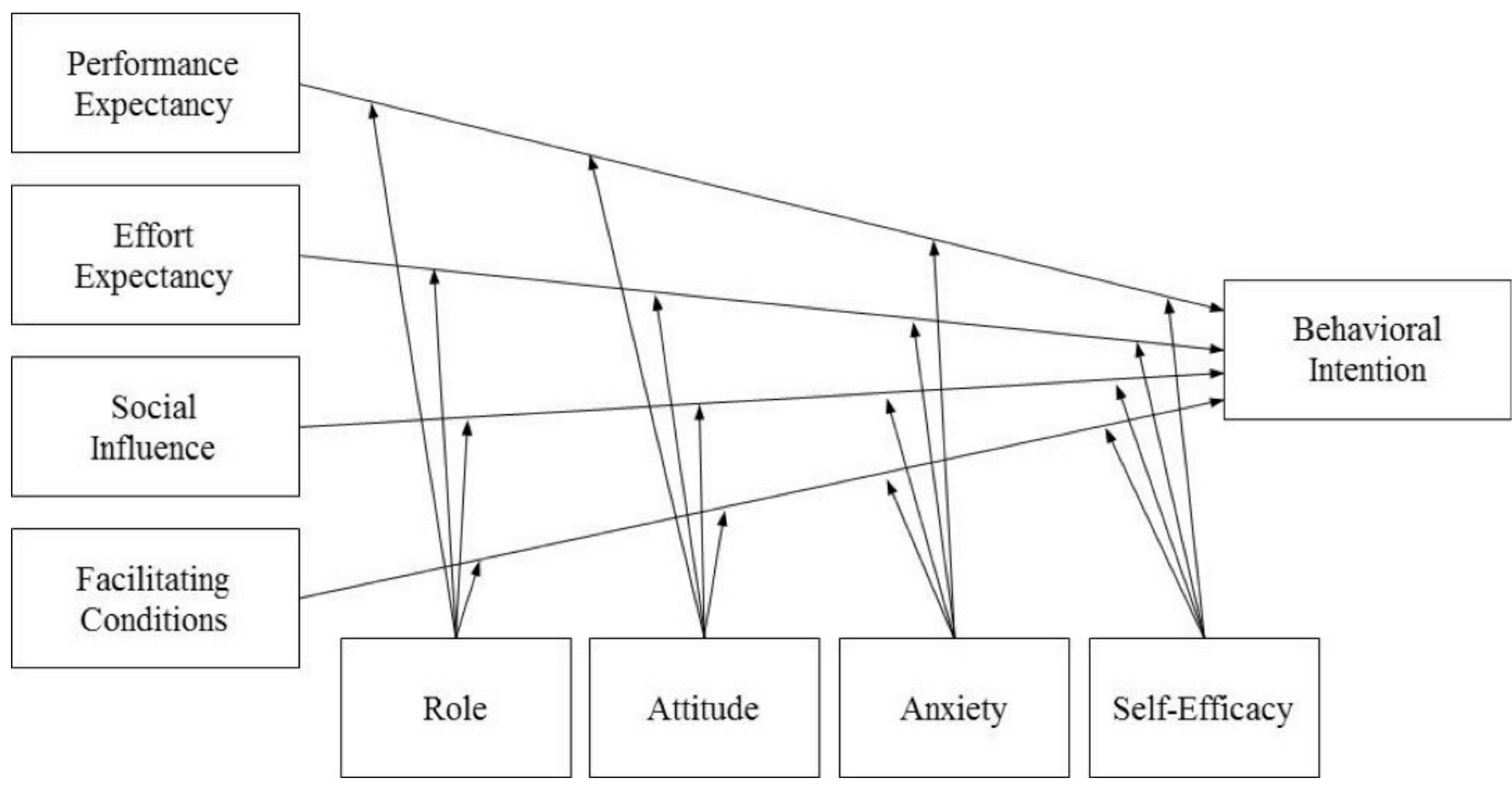

Figure I. Research Model

ISSN: 07 I8-2724. (http://www.jotmi.org)

Journal of Technology Management \& Innovation (c) Universidad Alberto Hurtado, Facultad de Economía y Negocios. 
Hypothesis I:The UTAUT model predicts behavioral intention to use telehealth equipment among a sample of patients, clinician, and agency leadership.

Hypothesis 2: Role, attitude, anxiety, and self-efficacy moderate the impact that UTAUT has on prediction of behavioral intention.

\section{Methodology}

This study utilized a cross-sectional survey design methodology to obtain data from a sample of research participants from Henry Ford at Home e-Home Care. Survey data were collected during the Fall 2012 using an online and a paperand-pencil self-report survey instrument.

\section{Participants}

Participants were comprised of patients, clinicians, and agency leadership personnel who were currently using or had experience using the Henry Ford at Home e-Home Care telehealth equipment. Eligible patients had a diagnosis of heart failure, chronic obstructive pulmonary disease (COPD), diabetes, or hypertension and were identified as potential participants for this study by the Telehealth medical administrative staff. Clinicians who had direct experience with the telehealth equipment were informed by the agency leadership to complete the online version of the survey. Finally, agency leadership with knowledge of the telehealth equipment participated online. Accordingly, 207 paper-based surveys were mailed via the U.S. postal service to patient participants that agreed to fill out the survey. Twenty seven paper-based surveys were returned via the Post and were manually entered into the web-based survey tool.

Clinicians and Agency Leadership completed the survey online while patients completed the survey using the paperbased instrument. A total of 134 responses were collected in the online tool with 130 clicking 'yes' to agree to take the survey and 4 clicking on 'no'. Of the 130 responses, 4 participants had no data and were deleted for a final sample size of 126 responses.

\section{Measures}

The survey instrument was comprised of demographic variables (i.e., role of participant, age, ethnicity, gender, education level, zip code, and comfort level with technology), 4 scales that measured the predictors $\mathrm{PE}, \mathrm{EE}, \mathrm{SI}$, and FC, 3 scales that measured the moderators attitude, anxiety, and self-efficacy, and I scale that measured the dependent variable behavioral intention (BI). The predictors and the moderators were scored along a 5-point Likert-type scale ranging from strongly disagree to strongly agree; the dependent variable was scored along a 6-point Likert-type scale ranging from not at all to 30 or more days 30 or more days. Four additional open-ended questions were asked to understand the reason for not wanting to use the Telehealth equipment, factors that might change the participants mind to use the equipment, and if the participate was willing to participate in a follow up interview.

\section{Data Analysis}

Study data were analyzed via descriptive statistics (mean and standard deviation), frequency counts and percentages of categorical variables including chi-square nonparametric test of the frequency distribution of each of the categorical variables, tests of the psychometric properties of multi-item variables via Cronbach's alpha measure of construct reliability and confirmatory factor analysis (CFA) measure of construct validity, correlation analysis, linear regression analysis, and structural equation modeling (SEM). $\mathrm{HI}$ was tested using $\mathrm{SEM}$, and $\mathrm{H} 2$ was tested using hierarchical linear regression. Mplus 7.II was used to perform the CFA and SEM analyses; Minitab 16.2.4 was used for all other statistical analyses. Chi-square,ANOVA, and linear regression tests of statistical significance were evaluated at the $95 \%$ level of significance (two-tail tests); Cronbach's alpha index of construct reliability was set at 0.7 or higher for acceptable reliability (Hinkin, 1998); and SEM models were evaluated using Comparative Fit Index (CFI) values of at least .90, Root Mean Square Error of Approximation (RMSEA) less than .08 , and the ratio of chi-square to the degrees of freedom $(\chi 2 / d f)$ less than 2 (Bentler, 1990; Bentler, 2007; Loehlin, 1998). 


\section{Results}

Gender, age, ethnicity, and education of participants, stratified by role (patients, $\mathrm{n}=20$; clinicians, $\mathrm{n}=84$; and agency leadership, $n=22$ ) are shown in Table I. Chi-square tests found the demographic characteristics were significantly distributed across participants. Specifically, the study sample was comprised of more females than males, more whites than non-whites, and more participants with a college degree than without a college degree.
The psychometric properties of the survey items used to measure the study variables in terms of the construct reliability and construct validity are shown in Table 2. Results found that alpha values for all study variables were $\geq .778$, the ratio of $\chi 2 / \mathrm{df}=1.8$, the RMSEA was .079 , and the CFI $=.924$. Taken together these results indicate the study variables were measured reliably and validly.

\begin{tabular}{|c|c|c|c|c|c|c|}
\hline \multirow[t]{2}{*}{ Characteristic } & \multicolumn{2}{|c|}{ Patients } & \multicolumn{2}{|c|}{ Clinicians } & \multicolumn{2}{|c|}{ Agency Leadership } \\
\hline & $\mathrm{n}$ & $\%$ & $\mathrm{~N}$ & $\%$ & $\mathrm{n}$ & $\%$ \\
\hline Total Sample & $20^{++}$ & 15.9 & 84 & 66.7 & 22 & 17.4 \\
\hline \multicolumn{7}{|l|}{ Gender } \\
\hline Female & 12 & 60.0 & $75^{* *}$ & 89.3 & 22 & 100.0 \\
\hline Male & 8 & 40.0 & 9 & 10.7 & 0 & 0.0 \\
\hline \multicolumn{7}{|l|}{ Age } \\
\hline $19-30$ & $0^{* * *}$ & 0.0 & $7^{* * k}$ & 8.3 & $0^{* * *}$ & 0.0 \\
\hline $31-40$ & 0 & 0.0 & 11 & 13.1 & 0 & 0.0 \\
\hline $41-50$ & 1 & 5.0 & 29 & 34.5 & 6 & 27.3 \\
\hline $51-60$ & 3 & 15.0 & 27 & 32.1 & 15 & 68.2 \\
\hline $61-70$ & 2 & 10.0 & 10 & 11.9 & 1 & 4.5 \\
\hline $70+$ & 14 & 70.0 & 0 & 0.0 & 0 & 0.0 \\
\hline \multicolumn{7}{|l|}{ Ethnicity } \\
\hline White/Non-Hispanic & 13 & 65.0 & $62^{* *}$ & 73.8 & $20^{* *}$ & 90.9 \\
\hline Black or African American & 7 & 35.0 & 12 & 14.3 & 2 & 9.1 \\
\hline Hispanic & 0 & 0.0 & 4 & 4.8 & 0 & 0.0 \\
\hline Asian & 0 & 0.0 & 4 & 4.8 & 0 & 0.0 \\
\hline No Response & 0 & 0.0 & 2 & 2.4 & 0 & 0.0 \\
\hline \multicolumn{7}{|l|}{ Education } \\
\hline Some high school & $I^{*}$ & 5.0 & $0^{* * *}$ & 0.0 & $0^{* * *}$ & 0.0 \\
\hline High school degree & 5 & 25.0 & 1 & 1.2 & 0 & 0.0 \\
\hline Some college & 8 & 40.0 & 4 & 4.8 & 1 & 4.5 \\
\hline Associate's degree & 1 & 5.0 & 25 & 29.8 & 7 & 31.8 \\
\hline Bachelor's degree & 2 & 10.0 & 37 & 44.0 & 13 & 59.1 \\
\hline Graduate degree & 3 & 15.0 & 17 & 20.2 & 1 & 4.5 \\
\hline
\end{tabular}

Table I. Characteristics of Sample by Age, Gender, Ethnicity, and Education

Note. Sample frequency is expressed as \% of all participants, $N=126$.

$++p<.01$ Chi-square test for equality of distribution across row.

$* \mathrm{p}<.05 * * \mathrm{p}<.0$ I Chi-square test for equality of distribution within column.

ISSN: 07 I8-2724. (http://www.jotmi.org) 


\begin{tabular}{|c|c|c|c|c|}
\hline Items & Mean $^{2}$ & $\mathrm{SD}^{3}$ & $a^{4}$ & $\mathrm{FL}^{5}$ \\
\hline UTAUT Model (PE, EE, SI, FC)' & & & .926 & -- \\
\hline Performance Expectancy (4 items) & 4.10 & 0.85 & .933 & 1.059 \\
\hline I find the equipment useful in managing my health & 4.19 & 0.87 & & .958 \\
\hline Using the equipment enables me to accomplish tasks quickly & 3.93 & 1.02 & & .809 \\
\hline Using the equipment allows me to be more involved & 4.08 & 0.92 & & .945 \\
\hline If I use the equipment, I will increase my chance of improving & 4.22 & 0.91 & & .874 \\
\hline Effort Expectancy (4 items) & 4.17 & 0.74 & .914 & .805 \\
\hline I expect my interaction with equipment will be understandable & 4.16 & 0.78 & & .922 \\
\hline I expect to find the equipment easy to use & 4.26 & 0.82 & & .878 \\
\hline I expect learning to operate the equipment is or has been easy & 4.14 & 0.83 & & .866 \\
\hline I expect to become skilled at using the Telehealth equipment & 4.15 & 0.86 & & .721 \\
\hline Social Influence 4 items & 3.81 & 0.84 & .865 & .883 \\
\hline People who influence my behavior think that I should use & 3.79 & 1.00 & & .751 \\
\hline People who are important to me think that I should use the & 3.76 & 1.04 & & .728 \\
\hline The doctors have been supportive in the use of the Telehealth & 3.86 & 0.92 & & .702 \\
\hline In general, the doctor has supported the use of the Telehealth & 3.87 & 0.86 & & .751 \\
\hline Facilitating Condition (3 items) & 4.34 & 0.71 & .801 & .914 \\
\hline I have the physical and mental ability necessary to use & 4.52 & 0.72 & & .708 \\
\hline I have the knowledge necessary to use Telehealth equipment & 4.23 & 0.85 & & .781 \\
\hline Support and assistance is available if I have difficulties & 4.35 & 0.73 & & .869 \\
\hline \multicolumn{5}{|l|}{ Moderating Variables (ATT, ANX, SE) } \\
\hline Attitude (3 items) & 4.18 & 0.84 & .872 & -- \\
\hline Using the Telehealth equipment is a good idea & 4.45 & 0.81 & & .878 \\
\hline Using the equipment makes managing my health interesting & 4.08 & 0.99 & & .874 \\
\hline I like working with the Telehealth equipment & 4.02 & 1.02 & & .809 \\
\hline Anxiety (4 items) & 2.03 & 0.84 & .929 & -- \\
\hline I feel nervous about using the Telehealth equipment & 1.98 & 0.93 & & .792 \\
\hline I worry that if I hit the wrong button my information may not & 2.16 & 0.94 & & .885 \\
\hline I hesitate to use the equipment for fear of making mistakes & 2.02 & 0.89 & & .902 \\
\hline The equipment is somewhat intimidating to me & 1.93 & 0.90 & & .939 \\
\hline Self-Efficacy (3 items) & 4.04 & 0.73 & .778 & -- \\
\hline I could complete most tasks without assistance & 3.89 & 0.96 & & .771 \\
\hline I could complete most tasks if I could call someone for help & 4.18 & 0.85 & & .647 \\
\hline I could complete most tasks with just the instructions provided & 4.03 & 0.81 & & .863 \\
\hline \multicolumn{5}{|l|}{ Dependent Variable (BI) } \\
\hline Behavioral Intention (2 items) & 3.30 & 1.99 & .941 & -- \\
\hline I intend to use the Telehealth equipment in the next ' $x$ ' days & 3.19 & 2.01 & & .791 \\
\hline I plan to use the Telehealth equipment in the next ' $x$ ' days & 3.39 & 2.10 & & 1.126 \\
\hline
\end{tabular}

Table 2. Construct Reliability and Validity of the UTAUT Model with Moderating Variables

Note. Psychometric properties conducted on data from the full sample of $\mathrm{N}=126$ study participants.

ITests of model fit for confirmatory factor analysis (CFA) of the UTAUT model with moderating variables: $\chi 2=524.03, \mathrm{df}=303, \mathrm{p}<$ .001 ; RMSEA $(90 \% \mathrm{Cl})=.078(.067-.089) ; \mathrm{CFI}=.917 .2$ Mean of items within scale where each item is measured on a 5-point Likert scale; $\mathrm{I}$ = strongly disagree, 5 = strongly agree. 3 Standard deviation. 4 Cronbach's alpha reliability measure of internal consistency. 5 Factor loading scores from CFA significant at $\mathrm{p}<.01$

ISSN: 07 I8-2724. (http://www.jotmi.org)

Journal of Technology Management \& Innovation (c) Universidad Alberto Hurtado, Facultad de Economía y Negocios. 


\begin{tabular}{|l|l|l|l|l|l|l|l|l|l|l|l|}
\hline & $\mathrm{M}$ & $\mathrm{SD}$ & $\mathrm{I}$ & 2 & 3 & 4 & 5 & 6 & 7 & 8 & 9 \\
\hline I.UTAUT & 4.07 & .72 & .926 & & & & & & & & \\
\hline 2. PE & 4.10 & .85 & $.877^{* *}$ & .933 & & & & & & & \\
\hline 3. EE & 4.17 & .74 & $.861^{* *}$ & $.667^{* *}$ & .914 & & & & & & \\
\hline $4 . \mathrm{SI}$ & 3.81 & .84 & $.847^{* *}$ & $.615^{* *}$ & $.607^{* *}$ & .865 & & & & & \\
\hline 5. FC & 4.34 & .71 & $.843^{* *}$ & $.594^{* *}$ & $.665^{* *}$ & $.632^{* *}$ & .801 & & & & \\
\hline 6.ATT & 4.18 & .84 & $.801^{* *}$ & $.879^{* *}$ & $.622^{* *}$ & $.616^{* *}$ & $.586^{* *}$ & .872 & & & \\
\hline 7.ANX & 2.03 & .84 & -.187 & -.038 & $-.222^{*}$ & -.109 & $-.271^{* *}$ & -.013 & .929 & & \\
\hline 8. SE & 4.04 & .73 & $.572^{* *}$ & $.405^{* *}$ & $.461^{* *}$ & $.369^{* *}$ & $.672^{* *}$ & $.364^{* *}$ & $-.292^{* *}$ & .778 & \\
\hline 9. BI & 3.30 & 1.99 & $.243^{*}$ & $.252^{*}$ & .150 & $.205^{*}$ & .185 & $.267^{* *}$ & .004 & .173 & $.94 \mathrm{I}$ \\
\hline
\end{tabular}

Table 3. Intercorrelations Between Study Variables

Note. $\mathrm{N}=126 . \mathrm{PE}=$ Performance Expectancy; $\mathrm{EE}=$ Effort Expectancy; $\mathrm{SI}=$ Social Influences; $\mathrm{FC}=$ Facilitating Conditions; $\mathrm{ATT}=\mathrm{At}-$ titude; $\mathrm{ANX}=$ Anxiety; $; \mathrm{SE}=$ Self Efficacy; $\mathrm{BI}=$ Behavioral Intention.

$*_{\mathrm{p}}<.05{ }^{* *} \mathrm{p}<.0$ I Pearson Product Moment Correlation. Cronbach's alpha measures of construct reliability are shown in the diagonal.

\begin{tabular}{|c|c|c|c|c|c|}
\hline Variable & Beta & Std Error & $\mathrm{T}$ & Sig & R-square \\
\hline UTAUT & $.827^{*}$ & .330 & 2.507 & .014 & $5.9 \%$ \\
\hline $\mathrm{PE}$ & .660 & .254 & 2.603 & .011 & 6.3 \\
\hline $\mathrm{EE}$ & .446 & .294 & 1.514 & .133 & 2.2 \\
\hline $\mathrm{SI}$ & .511 & .244 & 2.100 & .038 & 4.2 \\
\hline $\mathrm{FC}$ & .600 & .319 & 1.879 & .063 & 3.4 \\
\hline UTAUT & $.851^{*}$ & .333 & 2.554 & .012 & $6.3 \%$ \\
\hline Role & -.204 & .326 & -.626 & .533 & \\
\hline UTAUT & $2.527^{*}$ & 1.180 & 2.143 & .035 & $8.3 \%$ \\
\hline Role & 3.560 & 2.562 & 1.389 & .168 & \\
\hline UTAUT x Role & -.872 & .589 & -1.481 & .142 & \\
\hline Simple Slopes Analysis & & & $3.394^{+}$ & .001 & \\
\hline UTAUT & $3.122^{*}$ & 2.222 & 1.405 & .163 & $9.1 \%$ \\
\hline ATT & 2.819 & 1.848 & 1.526 & .130 & \\
\hline UTAUT $\times$ ATT & -.622 & .482 & -1.289 & .200 & \\
\hline Simple Slope Analysis & & & $4.783^{+}$ & .001 & \\
\hline UTAUT & -.200 & .868 & -.231 & .818 & $7.8 \%$ \\
\hline ANX & -2.038 & 1.646 & -1.238 & .219 & \\
\hline UTAUT x ANX & .506 & .382 & 1.326 & .188 & \\
\hline Simple Slopes Analysis & & & -.183 & .855 & \\
\hline UTAUT & $4.534^{*}$ & 1.820 & 2.492 & .014 & $10.3 \%$ \\
\hline SE & $4.025^{*}$ & 1.838 & 2.190 & .031 & \\
\hline UTAUT x SE & $-.957^{*}$ & .447 & -2.143 & .035 & \\
\hline Simple Slopes Analysis & & & $6.755^{+}$ & .001 & \\
\hline
\end{tabular}

Table 4. Prediction of Behavioral Intention by the UTAUT Model with Moderating Variables

Note. $\mathrm{N}=126$. See text for description of variables.

$* \mathrm{p}<.05 * * \mathrm{p}<.01$ Unstandardized regression coefficient

$+p<.01$ T-value for the simple slopes analysis of the medium level of the moderator

ISSN: 07 I8-2724. (http://www.jotmi.org)

Journal of Technology Management \& Innovation (c) Universidad Alberto Hurtado, Facultad de Economía y Negocios. 
The intercorrelations between the study variables are shown in in Table 3. Results found the UTAUT model was significantly correlated with behavioral intention to use the Telehealth equipment (BI).Additionally, from the set of moderators included in the study, attitude was found to be significantly correlated with BI.

We tested hypothesis I using both linear regression and structural equation modeling (SEM). Table 4 presents the results of linear regression analyses, which show that UTAUT is a significant predictor of behavioral intention to use Telehealth equipment $(\beta=.827, p<.05, \mathrm{R} 2=5.9 \%)$ alone and after controlling for the influence of role $(\beta=.85 \mathrm{I}, \mathrm{p}<.05$, $\mathrm{R} 2=6.3 \%$ ). In breaking down UTAUT into its constitutive elements of PE, EE, SI and FC, only the full UTAUT construct significantly predicted $\mathrm{BI}$.
Hypothesis I was also tested with SEM to model the complex relationship between the latent variable, UTAUT, and BI (see Figure 2). The overall fit of the model to the data using maximum likelihood (ML) estimation was excellent, resulting in $\chi^{2}=5.525, \mathrm{df}=9, \mathrm{p}=.786$; RMSEA $(90 \% \mathrm{Cl})=.000$ (.000-.069); and CFI = 1.000. According to the measurement model of the SEM, factor loadings of PE (.836), EE (.816), SI (.768), and FC (.709) onto the UTAUT latent variable were significant at $P<.01$. The structural model defined a significant prediction of $\mathrm{BI}$ by UTAUT when controlling for role $(\beta$ $=1.012, \mathrm{p}<.01, \mathrm{R} 2=12.9 \%)$.

Hypothesis 2 tested the moderation of the UTAUT-BI relationship by role, attitude, anxiety, and self-efficacy using linear regression and simple slopes analysis (Aiken \& West,

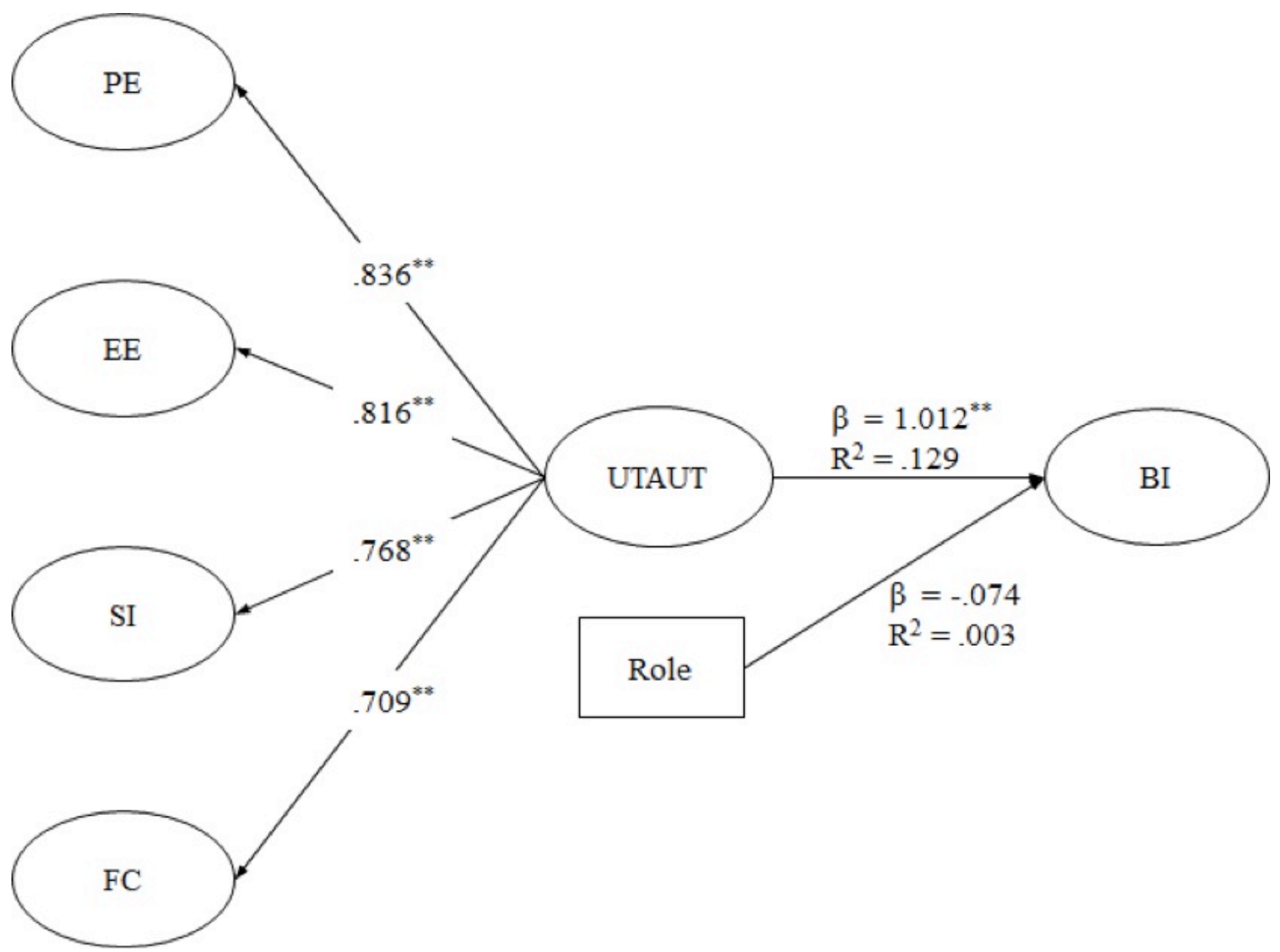

Figure 2. Latent variable path analysis model of UTAUT predicting BI

Note. Tests of model fit using maximum likelihood $(\mathrm{ML})$ estimation $(\mathrm{N}=126): \chi^{2}=5.525, \mathrm{df}=9, \mathrm{p}=.786 ; \mathrm{RMSEA}(90 \% \mathrm{Cl})=.000(.000-$ $.069) ; \mathrm{CFI}=1.000$.

** $\mathrm{p}<.0 \mathrm{I}$ Factor loadings, and unstandardized regression coefficient

ISSN: 07 I8-2724. (http://www.jotmi.org) 
1991; Dawson, 2013). As shown in Table 4, self-efficacy was the only moderator for which the interaction term, UTAUT $x$ moderator, was significant. On the other hand, simple slopes analysis found role, attitude, and self-efficacy were significant moderators. To facilitate the interpretation of the simple slopes analysis, Figure 3 shows plots of the UTAUT-BI relationship as moderated by role, attitude, anxiety, and selfefficacy. For role as a moderator, the plot of the regression of BI on UTAUT shows an inverted u-shape relationship, with UTAUT ultimately having the highest impact on BI for patients. For attitude and self-efficacy as moderators, both constructs function as positive moderators when UTAUT is low. When UTAUT is high, moderation is minimal for attitude, whereas for self-efficacy, moderation is highest when there is low-medium levels of self-efficacy, i.e., there are appears to be a ceiling effect for self-efficacy such that high levels of self-efficacy do not add to the impact of UTAUT on BI.
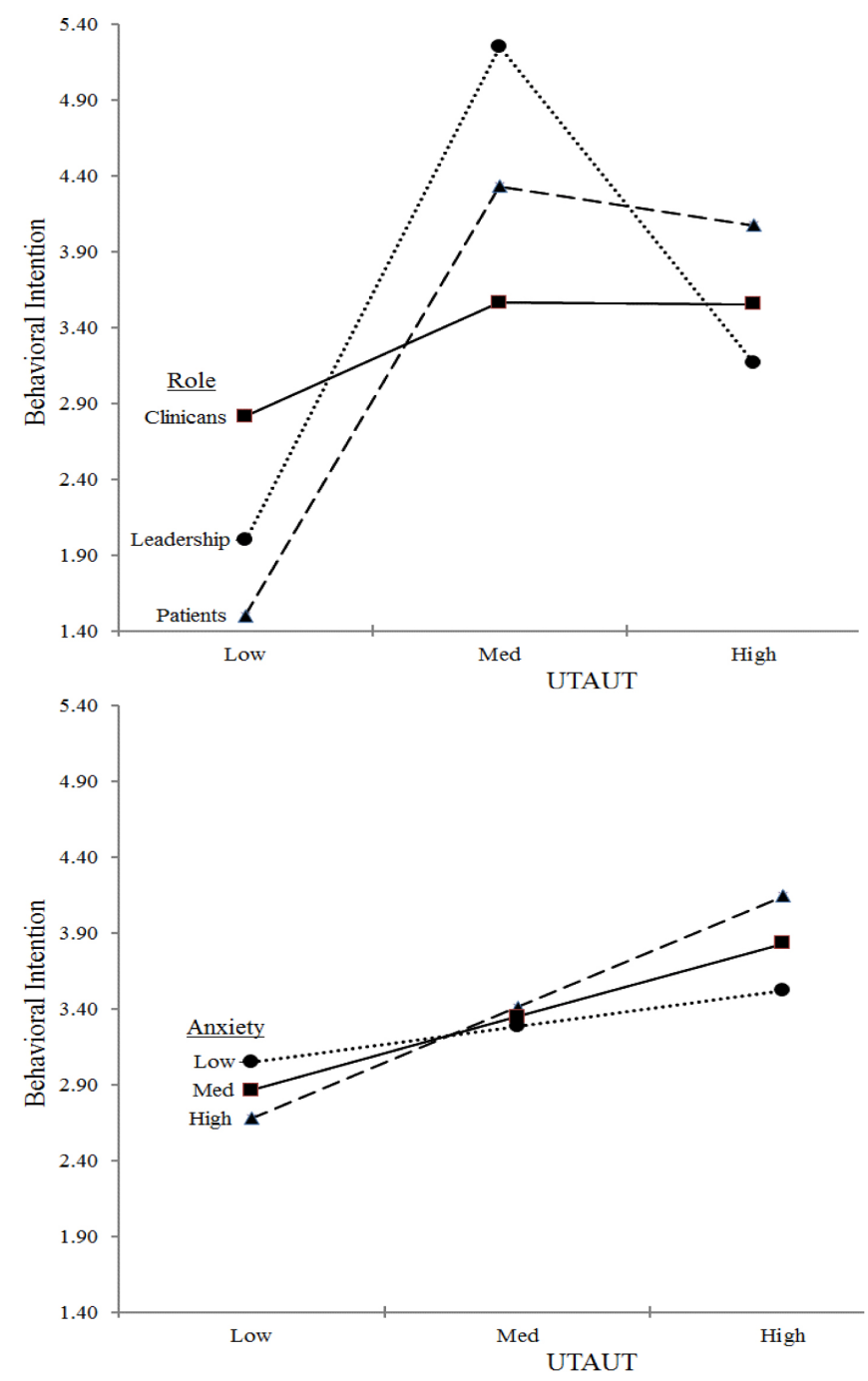

\section{Discussion}

We employed the unified theory of acceptance and use of technology (UTAUT) as the theoretical foundation to understand the behavioral intention of patients and clinicians to use the Henry Ford e-Home Health Care Telehealth equipment. The increased adoption of the telemedicine equipment has significant implications for the reduction of overall cost and reduction of unnecessary emergency room visits and hospital readmissions. It is important that clinicians become a stakeholder in the process of adopting the telehealth equipment. Having clinicians become aware of their attitudes toward the telehealth equipment, specifically their attitudes related to self-efficacy, will help identify those individuals who may be inhibitors in the adoption of the equipment.
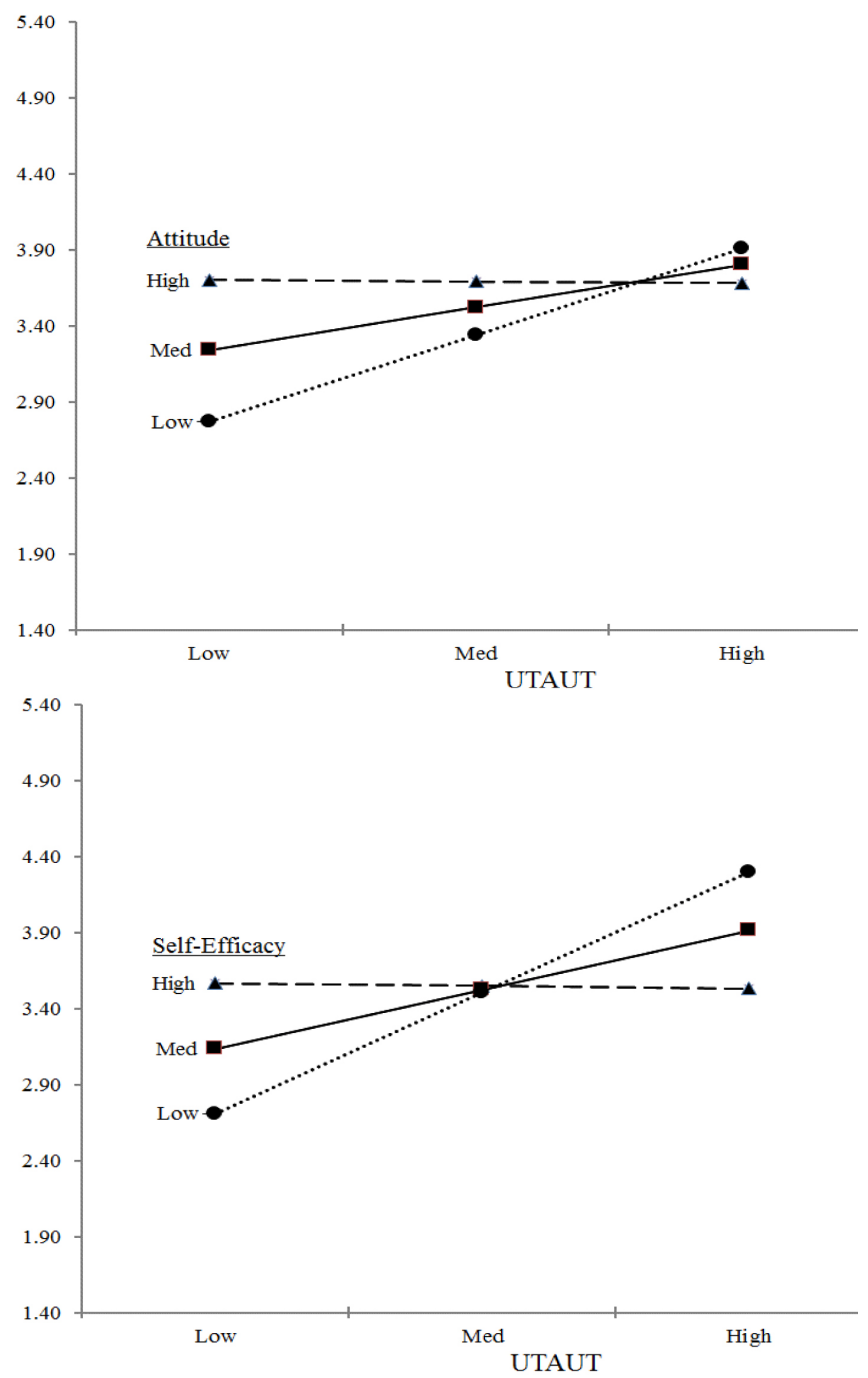

Figure 3. Plots of Role, Attitude, Anxiety, and Self-Efficacy as Moderators of UTAUT Predicting Behavioral Intention

ISSN: 07 I8-2724. (http://www.jotmi.org)

Journal of Technology Management \& Innovation (c) Universidad Alberto Hurtado, Facultad de Economía y Negocios. 
The data suggests that when clinicians have a high attitude [as measured on the survey such as using the equipment is a good idea, using the equipment makes managing the patient's health care more interesting, and like working with the equipment] coupled with a high perception of self-efficacy [I can complete most tasks with no assistance, I could call someone for help if I got stuck, I can complete most tasks with just the instructions provided me] the intention to use the equipment and the likelihood they will promote the technology is high when UTUAT is low-medium. Results found that clinicians will use the equipment if they feel that it will work. Results also found that there is minimal moderation of the UTAUT-BI relationship by anxiety. Nevertheless, data suggest that people who are anxious may be afraid they will make mistakes in using the equipment, e.g., they are worried that if they 'push a button, all the data will be lost'. Therefore, we recommend the design, creation, and delivery of workshops for the clinicians to provide the technical skills to help eliminate the anxiety of using the equipment to increase self-efficacy. The Agency Leadership needs to invest more time and have sessions where clinicians get to see and use the equipment in action.

The data suggest a strong relationship exists between UTAUT, self-efficacy, and behavioral intention to use the equipment [the expectation that their interaction with the equipment has been clear and understandable, the equipment will be easy to use, learning to use the equipment has been easy, and that they expect to become skilled in using the equipment]. Clinicians and patients will exert the effort to use the technology when they have a high expectancy that their effort will pay off. The 'payoff' is the intention to use the equipment, thus increasing the adoption rate. Telehealth is a good business model-it saves money, reduces unnecessary visits to the emergency room, and capitalizes on the importance of preventative medicine. We recommend the design and collection of outcome measures for those individuals using the equipment and the impact the use of the equipment is having on the health of the patients. Based on the results, workshops could be designed to increase awareness of what may be having significant benefits to the health of the patient. This benchmarking data could be useful in providing preventative care to show compliance with the Affordable Care Act of 2009.
The data also suggest that clinicians who are willing to learn are likely to adopt the technology. The component of selfefficacy must be present-a clinician will not spend 20 hours to learn how to do something if they think it will not be self-efficacious. We recommend the creation of an 'ambassador program' to recognize and reward clinicians in the form of rewards based on measurable outcomes. Rewards can be scheduled time off, gift cards to local restaurants, spas, bookstores, coffee shops, etc. Additionally, we caution that criterion to achieve the incentives must be made clear and in advance.

\section{Limitations and Future Research}

A significant limitation of this study was the small sample size of clinicians and patients. We need to learn the barriers to understand why clinicians and patients are inhibiting their use of the telemedicine technology. Future research could include a larger sample size with face-to-face qualitative interviews to shed light on specific areas that clinicians and patients are hesitant to use the equipment. A Questionnaire Protocol can be created to guide the interview process and the interviews can be digitally recorded and transcribed. A process of thematic analysis can be performed on the data to pinpoint and record patterns in the data to provide meaningful insights. 


\section{References}

AGGELIDIS, V.P. \& Chatzoglou, P.D. (2009) Using a Modified Technology Acceptance Model in Hospitals, International Journal of Medical Informatics, 78, II5-126. doi:10.1016/j. ijmedinf.2008.06.006.

AIKEN, L. S., \&West, S. G. (199I). Multiple regression:Testing and interpreting interactions. Newbury Park, London: Sage.

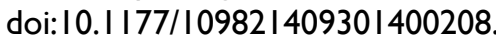

AJZEN, I. (|99|). The theory of planned behavior. Organizational behavior and human decision processes, 50(2), I79211. doi:10.1016/0749-5978(91)90020-T.

AJZEN, I., \& Fishbein, M. (1980). Understanding attitudes and predicting social behavior. Englewood Cliffs, NJ: Prentice-Hall.

BANDURA, A. (1994). Self-efficacy. In V.S. Ramachaudran (Ed.), Encyclopedia of human behavior (Vol. 4, pp.7I-8I). New York:Academic Press.

BRANCHEAU, J.C., Janz, B.D., \& Wetherbe, J.C., (1996). Key issues in information systems management: 199495 SIM Delphi results. MIS Quarterly, 20(2), 225-242. doi: 10.2307/249479.

BURTON-JONES, A., \& Hubona, G. S. (2005). Individual differences and usage behavior: revisiting a technology acceptance model assumption. ACM SIGMIS Database, 36(2), 58-77. doi:10.1/45//066/49.1066/55. doi:I0.I |45/I066|49.1066|55.

CHARLES, B.L. (2000). Telemedicine can lower costs and improve access. Healthcare Financial Management 54(4), 66-69.

COMPEAU, D.R. \& Higgins, C.A. (1995). Computer self-efficacy: Development of a measure and initial test. MIS Quarterly, 19 I89-2II.

DAWSON, J. F. (20I3). Moderation in management research: What, why, when and how. Journal of Business and Psychology, 29, I-19. doi:10.1007/x10869-013-9308-7.

DAVIS, F. (1989). Perceived usefulness, perceived ease of use and user acceptance of information technology. MIS Quarterly 13(3), 319-340. doi: 10.2307/249008.

ELIAS, S.M., Smith, W.L., \& Barney, C.E. (2012). Age as a moderator of attitude towards technology in the workplace: Work motivation and overall job satisfaction. Behaviour \& Information Technology, 3I(5), 453-467. doi:I0.108/0I4492 $9 \times .2010 .513419$.
FISHBEIN, M., \& Ajzen, I. (1975). Belief, attitude, intention, and behavior:An introduction to theory and research. Reading, MA:Addison-Wesley.

HARTWICK, J. \& Barki, H. ( I994). Explaining the role of user participation in information systems use. Management Science, 40(4), 440-465. doi: $10.1287 / \mathrm{mnsc} .40 .4 .440$.

HERTZ, B.T. (20I3). Telemedicine: Patient demand, cost containment drive growth. Medical Economics, 90(3), 37-42.

HINKIN, T. R., 1998. A brief tutorial on the development of measures for use in questionnaires. Organizational Research Methods, I(I), I04-12I. doi:I0.1 I77/I094428I9800100I06.

HOLDEN, R. J., \& Karsh, B.T. (20I0). The technology acceptance model: Its past and its future in health care. Journal of Biomedical Informatics, 43(1), 159-172. doi:10.1016/j. jbi.2009.07.002.

HSIA, R.Y., Kellermann, A., \& Shen, Y. (20I I). Factors Associated With Closures of Emergency Departments in the United States, The Journal of the American Medical Association, 305(19):1978-1985. doi:10.1001/jama.2011.620.

JIMISON, H.B. \& Sher, P.P. (1995). Consumer health informatics: Health information technology for consumers. Journal of the American Society for Information Science, 46(10), 783790. doi: I0.1002/(SICl) I097-457 I (I995 I 2)46: I0<783::AIDASII I>3.0.CO;2-L.

LEONG, L. (2003). Theoretical Models in IS Research and the Technology Acceptance Model (TAM). In C. Davis (Ed.), Technologies \& Methodologies for Evaluating Information Technology in Business (Pp. I-31). Hershey, PA: IRM Press. doi: |0.40|8/978-I-93177-748-3.ch00 I

MARKUS, M.L. \& Keil, M. (1994). If we build it, they will come: Designing information systems that people want to use. Sloan Management Review, 35(4), I I-25.

MATHIESON, K. (199I). Predicting user intentions: Comparing the technology acceptance model with the theory of planned behavior. Information Systems Research, 2(3), I73191. doi:10.1287/isre.2.3.173.

MOORE, G.C. \& Benbasat, I. (I99I). Development of an instrument to measure the perceptions of adopting an information technology innovation. Information Systems Research 2(3), 1992-222. doi: 10.1287/isre.2.3.192.z 
NUNDY, S., Dick, J., Goddu, A.P., Hogan, P., Lu, C.E., Solomon, M.C., Bussie, A., Chin, M.H.,Peek, M.E. (20I2). Using mobile health to support the chronic care model: Developing an institutional initiative. International Journal of Telemedicine and Applications, 2012. doi: I 0. I I55/2012/87/ 925.

ONG, C.S., Lai, J.Y., \& Wang, Y.S. (2004). Factors affecting engineers' acceptance of asynchronous e-learning systems in high-tech companies. Information \& Management, $4 \mathrm{I}(6)$, 795-804. doi: 10.1016/j.im.2003.08.012.

OR, C.K.L., Karsh, B., Severtson, D.J., Burke, L.J., Brown, R.L., \& Brennan, P.F. (20I I). Factors affecting home care patients' acceptance of a web-based interactive self-management technology. Journal of the American Medical Informatics Association, 20I I (I8), 5I-59. doi:I0.I I36/jamia.20 I0.007336.

O'REILLY, K.B. (20II,June I7).“Frequent-flier” ED users take toll on emergency physicians. American Medical News. Retrieved from http://www.amednews.com/article/201/0617/ profession/306179996/8/

PAVLOU, P.A. \& Fygenson, M. (2006). Understanding and predicting electronic commerce adoption: An extension of the theory of planned behavior. MIS Quarterly, 30(I), I I5-I43.

TAYLOR, S., \& Todd, P.A. ( 1995). Understanding information technology usage: A test of competing models. Information Systems Research, 6(2), I44-I76. doi: 10.1287/isre.6.2.144.

THAKUR, R. (20|3). Consumer adoption of mobile payment services by professionals across two cities in India: An empirical study using modified technology acceptance model. Business Perspectives \& Research, I (2), I7-29.

THOMPSON, R.L., Higgins, C.A., \& Howell, J.M. (I99I). Personal computing: Toward a conceptual model of utilization. MIS Quarterly, I5(I), I25-I43. doi: 1 0.2307/249443.

TOMPKINS, C. \& Orwat, J. (2010). A randomized trial of telemonitoring heart failure patients. Journal of Healthcare Management 55 3।2-322.

TRIANDIS, H.C. (1977). Interpersonal Behavior. Monterey, CA: Brooke/Cole.

VENKATESH,V., \& Davis, F.D. (2000).A theoretical extension of the technology acceptance model: four longitudinal field studies. Management Science, 46(2), 186-204. doi:10.1287/ mnsc.46.2.186.11926.

VENKATESH, V., Morris, M. G., Davis, G. B., \& Davis, F. D. (2003). User acceptance of information technology:Toward a unified view. MIS Quarterly, 425-478.
VISWANATHAN M, Kraschnewski J,Nishikawa B, Morgan LC, Thieda P, Honeycutt A, Lohr

$\mathrm{KN}$, Jonas $\mathrm{D}$. Outcomes of community health worker interventions. Evidence report/technology assessment No.18I. (Prepared by the RTI International-University of North Carolina Evidence-based Practice Center under Contract No. 2902007 l0056 I.) Rockville, MD : Agency for Healthcare Research and Quality, 2009.AHRQ Publication No. 09-E0 I4.

WILLS, M.J., El-Gayar, O.F., \& Bennett, D. (2008). Examining healthcare professionals' acceptance of electronic medical records using UTAUT. Issues in Information Systems, 9(2), 396-40I.

ZAI, A.H., Ronquillo, J.G., Nieves, R., Chueh, H.C., Kvedar, J.C., \& Jethwani, K. (20I3). Assessing hospital readmission risk factors in heart failure patients enrolled in a telemonitoring program International Journal of Telemedicine and Applications, 2013. doi: I0.1 155/2013/305819 